Xuan Yao 1,2,7, Megat Abd Hamid 1,2,7, Anand Sundaralingam ${ }^{3}$, Alice Evans ${ }^{4}$, Roshan Karthikappallil4, Tao Dong ${ }^{1,2}$, Najib M. Rahman ${ }^{3,4,5,6}$, Nikolaos I. Kanellakis ${ }^{3,4,5,6}$

nikolaos.kanellakis@ndm.ox.ac.uk

@NickKanellakis

\title{
Review
}

\section{Clinical perspective and practices on pleural effusions in chronic systemic inflammatory diseases}

Systemic inflammatory diseases are a heterogeneous family of autoimmune chronic inflammatory disorders that affect multiple systems within the human body. Connective tissue disease (CTD) is a large group within this family characterised by immune-mediated inflammation of the connective tissue. This group of disorders are often associated with pleural manifestations. CTD-induced pleuritis exhibits a wide variety of symptoms and signs including exudative pleural effusions and chest pain. Accurate estimation of prevalence for CTD-related pleuritis is challenging as small effusions are asymptomatic and remain undetected. Rheumatoid arthritis and systemic lupus erythematosus are frequent CTDs and present with pleural pathology in approximately $5-20 \%$ and $17-60 \%$ of cases, respectively. By contrast, pleural involvement in systemic sclerosis, eosinophilia-myalgia syndrome, mixed connective tissue disease, ankylosing spondylitis, polymyositis and dermatomyositis syndrome is rare. Clinical management depends on the severity of symptoms; however, most effusions resolve spontaneously. In this review we discuss the pathophysiological mechanisms and the clinical considerations of CTD-induced pleuritis.

\section{Educational aim}

- To discuss the pathophysiology, clinical perspectives and challenges of diagnosis and management of connective tissue disease-induced pleuritis.

Chronic inflammatory systemic disease (CID) by definition affects multiple organ systems and sometimes even the entire body. Connective tissue diseases (CTDs) are one such heterogeneous family of CIDs that are characterised by an autoimmune aetiology and can manifest within the connective tissue of any organ system [1]. They present with a wide range of signs and symptoms, often driven by specific circulating autoantibodies. CTDs can cause severe inflammation, tissue damage, abnormal repair and eventual loss of function, leading to long term morbidity and mortality and compromising quality of life.

Pleural involvement in CTD can present with effusion formation, or simply pleural inflammation and thickening. Therefore, presentations can vary

@ERSpublications

Chronic inflammatory diseases could cause pleural pathology. Clinical management depends on the

severity of symptoms, but most effusions resolve spontaneously. https://bit.ly/333euHb

Cite as: Yao X, Abd Hamid M, Sundaralingam A, et al. Clinical perspective and practices on pleural effusions in chronic systemic inflammatory diseases.

Breathe 2020; 16: 200203.

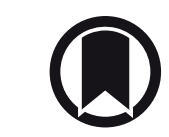

CrossMark 
from dyspnoea, to pleuritic chest pain and fever. Given many CTDs are rare diagnoses in their own right, there is a paucity of high-quality data in many of these conditions. It is therefore challenging to accurately estimate the true incidence of pleural involvement in some CTDs and further difficulties arise when dealing with mild or asymptomatic disease. Much of our understanding of CTDassociated pleural disease comes from older generation studies, using different diagnostic techniques to what is now seen as standard practice in the management of pleural disease. These advances in diagnostic methods have led to detection of disease at earlier stages and contributed to our understanding of the natural history and pathophysiology of these conditions.

Diagnosing CTD-associated pleural disease is often further complicated by the presence of increasingly common comorbidities that are themselves commonly associated with pleural involvement (e.g. cardiac disease or pneumonia) [2] The clinical management of CTD-associated pleural disease depends upon the underlying disease and the severity of symptoms. In this review, we discuss the pathophysiological mechanisms and the clinical management of CTD-associated pleural disease.

\section{Rheumatoid arthritis}

Rheumatoid arthritis (RA) is a systemic autoimmune inflammatory disease which primarily affects the synovial membrane within joints and leads to inflammation and subsequent cartilage and bone damage. While it may target any joint and extra-articular involvement is common, it most often affects the small joints of the hands and wrists [2, 3]. The clinical phenotypes of RA are diverse, depending on the pattern of joint involvement, degree of joint destruction, deformity and functional impairment, and extent of extraarticular involvement. On a molecular level, the disease is caused by autoantibodies produced by $\mathrm{B}$-cells which target the healthy joint tissue. The antibodies initially lead to inflammatory swelling and hypertrophy of the synovial membrane with subsequent loss of cartilage density, symmetric polyarthritis, and finally joint, bone and cartilage destruction [4]. The global incidence of RA is estimated between $0.25 \%$ and $1 \%$ and it is seen more commonly in females and smokers [5]. Every year there are 40 new cases per 100000 of the population in Europe and the USA. Studies looking into survival of patients with RA show significantly lower life expectancies when compared to the whole population as a whole. RA mortality rates have been decreasing over the past few years as patients are diagnosed at an earlier stage and therapies become more effective, but RA patients still exhibit a significantly higher risk of death compared with the general patient population. There is a strong genetic component, particularly in seropositive disease, with heritability estimated at $40-65 \%$. The human leukocyte antigen (HLA) system has been particularly implicated in this, but other genetic loci are also suspected. Extra-articular manifestations in RA are far reaching and can include: skin, mucous membranes, heart, lungs, eyes, nervous system, haematological and vascular involvement [6].

Reliable estimates on the incidence and prevalence of RA-associated pleural disease are hard to come by due to a paucity of large datasets. Nonetheless, it is estimated that the annual incidence of RA-associated pleural disease is $0.34 \%$ in females and $1.54 \%$ in males and a prevalence of $5 \%$ [7]. Interestingly, autopsy studies reveal a much higher rate of pleural disease than identified in life [2]. It is the commonest form of RA-associated lung disease, although interstitial lung disease (ILD) and airway centric disease is also closely associated. RA-associated pleural disease is more frequently seen in middle-aged ( $>50$ years) males than females and is particularly prevalent in those with long-term arthritis, smoking history and other lung-related diseases [8-10].

The disease usually manifests with pleural thickening with or without effusion. Patients may remain asymptomatic with small effusions, but can become increasingly symptomatic with increasing size. The main symptoms reported are chest pain, fever and dyspnoea [11, 12]. It is worth mentioning that in a small number of patients pleural involvement can occur prior to the onset of joint disease and similar observations have been noted with RA-associated ILD [2, 13]. Effusions in rheumatoid pleuritis are exudative and in $70 \%$ of cases are unilateral on the left side. However, bilateral pleural effusions have been detected. Macroscopically the pleural fluids appear milky, cloudy, serous or greenish-yellow. Clinical signs of effusions in rheumatoid pleuritis include a titre of rheumatoid factor (RF) $>1: 320$ present in the pleural fluid, glucose levels between 10 and $30 \mathrm{mg} \cdot \mathrm{dL}^{-1}$, lactate dehydrogenase (LDH) levels $>1000 \mathrm{U} \cdot \mathrm{L}^{-1}$, pleural fluid acidosis with $\mathrm{pH}<7.2$, high total protein, presence of single or multiple pleural nodules (diameter range: $2-7 \mathrm{~mm}$ ) and high cholesterol (table 1) [12, 14]. Moreover, pleural effusions in rheumatoid pleuritis exhibit increased production of the complement protein SC5b-9 and decreased levels of C 3 and C4 compared with pleural effusions of other aetiology. The acidification of the pleural fluid in rheumatoid pleuritis is caused by increased hydrogen ion flux across the pleural membrane, which induces local metabolic activity and triggers the production of lactic acid and carbon dioxide [15]. Low glucose levels are a characteristic trait of rheumatoid pleuritis. Studies have shown that $-80 \%$ of rheumatoid pleuritis patients exhibit serum levels of glucose at least two times higher than in pleural fluid. It is likely that the induced metabolic activity increases glucose consumption in the pleura and therefore pleural fluid glucose level is low. The identity of the cell, or cells, that utilise 
Table 1 Incidence and clinical signs of pleural involvement in chronic systemic inflammatory diseases

\begin{tabular}{|c|c|c|c|c|}
\hline CTD & $\begin{array}{l}\text { Pleural effusion } \\
\text { incidence } \\
\text { (of CTD patients) }\end{array}$ & $\begin{array}{r}\text { Macroscopic } \\
\text { appearance }\end{array}$ & \multicolumn{2}{|c|}{ Clinical signs } \\
\hline Rheumatoid arthritis & $5-20 \%$ & $\begin{array}{l}\text { Milky, cloudy, } \\
\text { serous or } \\
\text { green-yellowish }\end{array}$ & $\begin{array}{c}\text { Exudative effusion, } \\
\text { RF titre } \geq 1: 320, \\
\text { Glucose } 10-30 \mathrm{mg} \cdot \mathrm{dL}^{-1}, \\
\mathrm{LDH} \geq 1000 \mathrm{U} \cdot \mathrm{L}^{-1}, \\
\mathrm{pH}<7.2, \\
\text { High total protein, } \\
\text { High cholesterol } \\
\text { Single or multiple pleural nodules }\end{array}$ & $\begin{array}{l}\text { Enriched in eosinophils } \\
\text { and macrophages } \\
\text { (multinucleated) } \\
\text { Presence of rheumatoid } \\
\text { arthritis cells }\end{array}$ \\
\hline $\begin{array}{l}\text { Systemic lupus } \\
\text { erythematosus }\end{array}$ & $17-60 \%$ & $\begin{array}{l}\text { Yellow or } \\
\text { serosanguineous }\end{array}$ & $\begin{array}{c}\text { Exudative effusion, } \\
\text { Glucose } 60 \mathrm{mg} \cdot \mathrm{dL}^{-1}, \\
\mathrm{LDH}<500 \mathrm{IU} \cdot \mathrm{L}^{-1} \\
\mathrm{pH}>7.3 \\
\text { Total protein }>3.5 \mathrm{~g} \cdot \mathrm{dL}^{-1}, \\
\text { Antinuclear antibody } \\
\text { titres } \geq 1: 160\end{array}$ & $\begin{array}{c}\text { Enriched in macrophages, } \\
\text { neutrophils, basophils, } \\
\text { eosinophils and } \\
\text { lymphocytes }\end{array}$ \\
\hline $\begin{array}{l}\text { Eosinophilic } \\
\text { granulomatosis with } \\
\text { polyangiitis }\end{array}$ & $29 \%$ & & Exudative effusion & \\
\hline $\begin{array}{l}\text { Granulomatosis with } \\
\text { polyangiitis }\end{array}$ & $5-55 \%$ & & $\begin{array}{c}\text { Exudative effusion } \\
\text { Total protein } 3.8-5.7 \mathrm{mg} \cdot \mathrm{dL}^{-1}\end{array}$ & $\begin{array}{c}\text { Enriched in } \\
\text { neutrophils and other } \\
\text { polymorphonuclear cells }\end{array}$ \\
\hline Systemic sclerosis & $7 \%$ & & $\begin{array}{l}\text { Exudative effusion } \\
\qquad \mathrm{pH}>7.2\end{array}$ & \\
\hline $\begin{array}{l}\text { Mixed connective } \\
\text { tissue disease }\end{array}$ & $6-50 \%$ & & Exudative effusion & $\begin{array}{c}\text { Enriched in } \\
\text { polymorphonuclear } \\
\text { leukocytes }\end{array}$ \\
\hline
\end{tabular}

the glucose consumption remains unclear. Another theory suggests that glucose transportation from the systemic circulation to pleural fluid is hindered by the thickening of both the parietal and visceral pleura. To this end, epithelial cells replace the mesothelial population.

The pleural cavities of patients presenting with rheumatoid pleuritis are characterised by infiltration by inflammatory cells. Cytologically these pleural effusions are enriched in lymphocytes (lymphocytosis) and elongated and multinucleated histiocytes [16]. It is well-established that RA patients have dysregulated immune systems, with increased production of autoantibodies. However, the exact molecular pathways that promote the infiltration of the pleura are unknown.
The majority of RA-associated effusions will resolve spontaneously or with the initiation of specific RA treatment and thus do not necessitate additional management strategies. In cases of breathlessness and chest pain, thoracocentesis is recommended and certainly if the diagnosis is in doubt. This may need extending to include pleural biopsy procedures, again if the diagnosis is in doubt and risk factors for malignancy are present. Oral and intrapleural corticosteroids may be administered in cases of persistent effusion to aid resolution. Furthermore, intrapleural fibrinolytics may be trialled if effusion is complicated by infection. Patients with persistent dyspnoea due to pleural thickening and restrictive lung deficit can be offered a lung-release surgical decortication to allow lung re-expansion [12]. 


\section{Systemic lupus erythematosus}

Systemic lupus erythematosus (SLE) is a chronic autoimmune disease of multifactorial aetiology, with genetic susceptibility, environmental triggers and derangement within the innate and adaptive immune system all shown to play a part [17]. The condition primarily affects females of childbearing age and this is attributed to the effects of the female sex hormone on the immune system. A failure to adequately clear the debris of apoptotic cells results in the development of antinuclear antibodies (ANA), which subsequently gives rise to the wide range of effects seen $[18,19]$. The incidence and prevalence of SLE are seen to be increasing through a combination of early diagnosis and improved survival. There is a marked increase in prevalence in African American populations with a similar yet less notable risk in other ethnic minority groups. There are $\sim 1.5$ million patients with SLE in the USA. Early diagnosis and improved patient management have increased the 10-year survival to $70 \%$ [18].

Symptoms are diverse and reflect the multisystem nature of SLE. These include: fatigue, fever, malar rash, lymphadenopathy, arthralgia, chest pain, oral ulceration and neuropsychiatric disturbance [18]. These form part of the 2019 European League against Rheumatism/American College of Rheumatology (EULAR/ACR) classification criteria. Presentation with pleural effusion is one of the major diagnostic criteria for SLE and reflects how commonly it is observed [20]. Pleural involvement is part of the spectrum of serosal disease observed in SLE and other serosal membranes can also be involved (pericardium, peritoneum).

Pleural effusions occur in $~ 17-60 \%$ of SLE patients and are the most common pulmonary manifestation of the disease [21-23]. It is seen to occur more frequently in patients with late-onset disease ( $>50$ years of age, $31.9 \%$ versus $18.4 \%$ ) [ 19 , 24]. Transient lupus pleuritis can be asymptomatic and makes it harder to estimate the true incidence. Data from post-mortem examination studies suggest that lupus pleuritis may occur in up to $93 \%$ of SLE cases [21, 25]. However, this increase could also be attributed to secondary superadded comorbidities (cardiac failure, pleural infection, drug-related).

Pleuritic chest pain is a common symptom (45$60 \%$ of cases), and may manifest with or without pleural effusion alongside dyspnoea, tachycardia, cough and fever [26]. Inflammation triggering increased vascular permeability and diminished pleural fluid absorption are believed to contribute to the accumulation of the excess volume of pleural fluid in SLE patients. Effusions can also be related to medication associated with treatment of SLE [27, 28]. However, the exact molecular mechanisms remain unknown [26].

Pleural effusions in SLE are predominately exudative, bilateral and of small to moderate volume. However, large volume or unilateral effusions have been reported with similar distribution between right and left hemithoraces [21]. Macroscopically the pleural fluid appears yellow or serosanguineous. Biochemically pleural fluid is characterised by a total protein concentration $>3.5 \mathrm{~g} \cdot \mathrm{dL}^{-1}$, glucose levels around $60 \mathrm{mg} \cdot \mathrm{dL}^{-1}$, $\mathrm{pH}>7.30$ and low LDH levels usually $<500 \mathrm{IU} \cdot \mathrm{L}^{-1}$ (table 1) [29]. Lupus pleuritis effusions exhibit lower levels of the complement proteins C1q, C3 and C4 compared with effusions seen in other CTDs. However, these differences have limited diagnostic potential as decreased complement protein levels have also been found in RA pleural effusions. The combination of pleural fluid ANA titre $\geq 1: 160$, with homogeneous pleural fluid ANA staining patterns and pleural fluid to serum ANA titre ratios $\geq 1$ have been suggested as diagnostic tools for lupus pleuritis [30]. Cytologically, pleural effusions in SLE are enriched in macrophages, neutrophils, basophils and eosinophils followed by lymphocytes in cases of persistent effusions. Lupus erythematosus cells may be detected although they are not indicative of SLE, as they have been reported in pleural effusions not induced by SLE [31]. Immunohistological examination of pleural tissue biopsies from lupus pleuritis patients reveal deposition of IgG, IgM and $\mathrm{C} 3$ immunoglobulins which show diffuse and speckled patterns within the pleural nuclei [32, 33].

The clinical management SLE-associated pleural disease is guided by the severity of the symptoms. In most cases, small effusions are asymptomatic and self-resolve. In patients with pleuritic chest pain, nonsteroidal anti-inflammatory drugs (NSAIDs) or a short course of oral corticosteroid are highly effective. While in more resistant cases higher doses or the use of additional immunosuppressants (azathioprine, hydroxychloroquine, cyclosporine, intravenous immunoglobulin) may be required and have been described in the literature [1, 9]. In cases of large volume pleural effusion, in order to alleviate chest pain and breathlessness thoracocentesis is suggested. Patients with chronic lupus pleuritis effusions are rare, but have been successfully managed with chemical pleurodesis using talc or tetracycline in limited case series [34, 35]. Pleural involvement has been reported as a negative predictor of survival [36]

\section{Eosinophilic granulomatosis with polyangiitis}

Eosinophilic granulomatosis with polyangiitis (EGPA) is a rare autoimmune disease first described in 1951 by Jacob Churg and Lotte Strauss as allergic granulomatosis [37]. This name references the characteristic necrotising vasculitis and the presence of eosinophilic granulomas thought to be at the heart of the pathology. EGPA is characterised by a clinical triad of asthma, eosinophilia and vasculitis. 
A stepwise progression of the condition has been noted with a prodromal phase of asthma, rhinitis and sinusitis followed by a second phase comprised of an eosinophilia and the final phase of vasculitis [38].

Pleural involvement is common in diseases producing vasculitis due to the complexity of the vasculature supplying the lungs and pleura [39]. In EGPA, case series have suggested $18-29 \%$ of patients experience pleural effusion [40]. Pleural fluid typically demonstrates an eosinophilic exudative effusion (table 1) [38]. Lung biopsy shows an abundance of inflammatory cells leading to vasculitis and infarction of the subpleural lung parenchyma and therefore increased permeability of the microcirculation. Lymphatic dilation and blockage are thought to be another key component in the development of pleural effusion, it is caused by the infiltration of eosinophils within the subpleural connective tissue [41, 42]. There is variation in the prevalence of pleural effusion depending on antineutrophil cytoplasmic antibody (ANCA) status. A positive result in EGPA generally involves perinuclear ANCA with myeloperoxidase antibodies. A negative ANCA was more frequently associated with pleural involvement alongside other pulmonary and cardiac manifestations, while a positive ANCA shows greater predilection for renal disease [43]. Although pleural involvement is common in EGPA, effusions can normally be managed with oral corticosteroids. Longer term treatment should focus on treating the underlying vasculitis itself.

\section{Granulomatosis with polyangiitis}

Granulomatosis with polyangiitis (GPA) is also a vasculitides similar to EGPA. The pathological hallmarks are a necrotising granulomatous vasculitis typically affecting the small vessels of the upper and lower respiratory tract and the kidneys [44-46]. GPA does not involve eosinophilia, although atypical phenotypes demonstrating EGPA-like peripheral eosinophilia, but without the asthma-like symptoms have been described [47].

Chest pain is a common symptom in GPA, although it appears to be nonspecific. The incidence of pleural effusion is variable and ranges between $5 \%$ and $55 \%$ [48-50]. The cause of pleural involvement is unknown, although the vasculitisinduced parenchymal infarction implicated in EGPA has also been observed in GPA [51, 52]. The pleural effusions are exudative, typically small and unilateral showing an abundance of polymorphonuclear cells (mainly neutrophils) [52]. Total protein concentration ranges between 3.8 and $5.7 \mathrm{mg} \cdot \mathrm{dL}^{-1}$ (table 1 ). Pleural effusions will generally resolve following treatment of the underlying GPA with corticosteroids or stronger immunosuppressants such as cyclophosphamide [52]. Although rare, case reports of spontaneous pneumothorax and pyopneumothorax through rupture of a cavitating nodule have also been reported in the literature [53].

\section{Systemic sclerosis}

Systemic sclerosis (SSc), also known as scleroderma, is an uncommon autoimmune disease of unknown aetiology that affects around 1 in 10000 of the population. It is characterised by immune activation, widespread microangiopathy and fibrosis within the connective tissue of blood vessels, skin and internal organs. Pathophysiological mechanisms involve the production of antibodies which target the kinetochore of chromosomes, leading to an accumulation of T-cells which stimulate fibroblast activity and collagen deposition in tissues. Recent research suggests that some subsets of SSc may be caused by a maladaptive immune response to a tumour antigen, which results in an autoimmune response to specific nuclear antigens in tumour cells. This might explain the increased risk of cancer seen in patients with SSc [54]. Diagnosis is supported by the presence of autoantibodies; specifically, anti-centromere, anti-topoisomerase and anti-RNA polymerase III antibodies. Distinct autoantibody profiles are associated with specific internal organ complications, which allows stratification of treatment. In a similar manner to SLE, the EULAR/ACR have designated classification criteria for its diagnosis.

Clinically, SSc can be divided into "limited" and "diffuse" subtypes. Limited SSc causes sclerosis of the skin distal to the elbows and knees. Diffuse SSc, in contrast, can affect the proximal limbs and trunk. Symptoms include arthritis, reduced joint mobility, impaired lung function and renal disease. The latter has been identified as a poor prognostic indicator with the potential to lead to a fatal scleroderma renal crisis. Diffuse SSc has a worse prognosis due to greater involvement of internal organs, with cardiopulmonary manifestations being the most common cause of death.

Despite a lack of disease modifying drugs, overall outcomes and survival have improved over the past four decades due to early screening and improvements in the treatment of organ-specific complications [55].

It is important to note that both ILD and pulmonary vascular disease are both far more common manifestations of pulmonary disease in SSc. Nonetheless pleural involvement occurs in 7\% of SSc patients and is more frequent in the diffuse subtype of the disease (10\%) [56]. The exact incidence may be higher as most effusions are small and asymptomatic and thus remain undiagnosed. Its pathogenesis may relate to pleural vasculitis or concomitant heart failure. Pleural effusions are exudative with a $\mathrm{pH}$ $>7.2$. Several case studies suggest an elevated serum CA-125 may be one of the indicators of serositis and 
pleural effusion in SSc, as CA-125 levels are usually normal in collagen vascular disease in the absence of pleural involvement (table 1) [57]

\section{Ankylosing spondylitis}

Ankylosing spondylitis (AS) is a chronic inflammatory disease that primarily affects the axial skeleton and peripheral joints. It is strongly associated with the HLAB27 gene; however, fewer than $5 \%$ of B27 positive individuals in the general population become affected [58]. Genome-wide association studies have also demonstrated the impact of genes outside the major histocompatibility complex. AS tends to develop in teenagers and young adults, with a peak age of onset between 20 and 30 years. It causes inflammatory back pain and stiffness, arthritis, enthesitis and fatigue. AS is a seronegative spondyloarthropathy, and so diagnosis is confirmed by radiography of the sacroiliac joints and spine. Although AS does not significantly affect life expectancy, mortality is increased in AS patients, secondary to cardiovascular disease. AS also increases the risk of osteoporosis, spinal fractures and chest infections. There is no current cure for AS, but treatment with NSAIDs and tumour necrosis factor (TNF) inhibitors, as well as physiotherapy, can delay or slow the progression of the disease and alleviate symptoms [59].

Whilst chest wall deformity, causing a restrictive defect, is the commonest pulmonary complication in AS patients, atypical fibrobullous lung disease and pleural manifestations are rare [60]. When present, effusions are usually exudative with $\mathrm{pH}>7.3$ and glucose $>30 \mathrm{mg} \cdot \mathrm{dL}^{-1}$ (table 1 ). It is believed that they are caused by the spread of vertebral inflammatory fibrosis into pulmonary tissue and the subpleural space. Case studies suggest that use of TNF inhibitors to treat AS can cause interstitial disease or drug-induced lupus serositis, resulting in pleural and pericardial effusions that improve following withdrawal of the drug [61].

\section{Idiopathic inflammatory myopathies}

Idiopathic inflammatory myopathies (IIMs) are a group of CTDs characterised by chronic inflammation and weakness of skeletal muscles. Under the 2017 joint classification criteria of the EULAR/ACR, most IIM patients fall into the subgroups of polymyositis (PM), dermatomyositis (DM), or inclusion-body myositis (IBM) [62]. Extramuscular involvement is frequently seen. Pulmonary disease is the most frequent and is seen in $\sim 50 \%$ of cases of PM and DM, where it takes the form of ILD [1]. Other associations include the characteristic skin rash seen in DM and malignancy. Patients present with symmetrical muscle weakness of the proximal limbs and trunk. Diagnosis relies on detection of elevated muscle enzymes (serum creatine kinase up to 50 times the upper limit of normal) and electromyography and histological analysis of a muscle biopsy. Prognosis for both PM and DM is poor, with a 10-year estimated survival of 62\% [63].

Although overt clinical or radiological evidence of pleural involvement in IIM patients is rare, it has been reported in PM and DM, and is probably caused by locally driven immune pleuritis associated with underlying ILD. It has been suggested that the pathogenesis could be due to complement activation within the pleural microvasculature resulting in pleuritis and effusion [64]. Given the strong association of DM with an underlying malignant process, these effusions should always be sampled and in persistent cases strong consideration should be given towards obtaining a pleural biopsy.

\section{Sjögren's syndrome}

Sjögren's syndrome (SS) is a systemic autoimmune disease that mainly affects the mucosal surfaces, including lacrimal and saliva glands, causing exocrinopathy $[65,66]$. The severity of symptoms varies among patients and could compromise the quality of life. The major manifestations include dry eyes, dry mouth, dental disease, joint pain and malaise which can remain steady or progress over time. Furthermore, swelling of the salivary and parotid glands is a common manifestation. SS patients are at risk to develop non-Hodgins's lymphoma [66]. SS can occur at any age; however, it is more common in women between the ages of 45 and 55 years $[67,68]$. Approximately half of the SS cases are primary and the other half occur with another underlying autoimmune CTD (RA, $\mathrm{SLE}, \mathrm{SSC}$ ). Due to the nature and wide variety of symptoms diagnosis is challenging and relies on physical examination (eye, oral and dental) and blood tests [66, 69, 70].

While pleural involvement is rare in primary SS, it is more common in patients with SS secondary to another CTD [71-75]. Pleural effusions are typically bilateral and exudative; however, cases of unilateral effusions have been reported [71, 76, 77]. Pleural fluids are usually enriched in $\mathrm{CD}^{+}$and $\mathrm{CD} 2 \mathrm{O}^{+}$ $\mathrm{B}$-lymphocytes and have physiological $\mathrm{pH}$ and glucose levels, but a low concentration of adenosine deaminase [77]. Moreover, SS-induced pleural fluids are positive for RF, ANA and anti-SS-A and antiSS-B antibodies [8]. In most cases pleural effusions resolve spontaneously; however, corticosteroids can be administered if they persist [78].

\section{Mixed connective tissue disease}

Mixed connective tissue disease (MCTD) is a complicated autoimmune systemic disease, 
which presents a mixture of features from other autoimmune disorders like SLE and SSc [79, 80]. Symptoms include fever, fatigue, joint pain, rash and swollen fingers. Diagnosis is complicated as symptoms do not manifest at once. MCTD usually presents in combination with SS and thus is referred to as an overlap disease. MCTD patients exhibit high blood levels of U1 small nuclear ribonucleoprotein. The cause of MCTD remains unknown and treatment options are not available.

MCTD-induced pleural involvement could occur; however, the incidence varies [81-84]. The exact molecular mechanism of pleural effusion development remains to be identified. Pleural fluid may accumulate due to inflammation of the serous membranes (serositis) or adjoining intercostal muscles [85]. Pleural effusions are often exudative, enriched in polymorphonuclear leukocytes and show high levels of total protein and LDH [86].

\section{Conclusion}

CTD-associated pleural disease remains an underexplored area of medicine. This is in part due to the underlying prevalence of the respective conditions, which has hindered further study through large datasets. Nevertheless, the prevalence of CTD has been increasing, in part due to earlier diagnosis but also as a result of improved survival. As a result, we are seeing CTD within an increasingly elderly and morbid population. Within this population there are added difficulties in diagnosing and managing CTD-associated pleural disease, due to the presence of confounding comorbidities. Further research through large international registries in the current era, with our modern diagnostic methods, is what is truly needed to understand the burden of disease and map out the pathophysiological mechanisms in order to identify diagnostic and prognostic markers and improve treatment as a whole.

\section{Key points}

- Chronic inflammatory diseases, such as connective tissue disease, cause pleural pathology including pleural effusion, chest pain, fever and dyspnoea.

- Rheumatoid arthritis and systemic lupus erythematosus are connective tissue diseases that frequently involve the pleura, causing exudative effusions.

- Clinical management depends on the severity of the symptoms, with most effusions resolving spontaneously.

- Pleural involvement in systemic sclerosis, eosinophilia-myalgia syndrome, mixed connective tissue disease, ankylosing spondylitis, polymyositis and dermatomyositis syndrome is rare.

\section{Affiliations}

Xuan Yao ${ }^{1,2,7}$, Megat Abd Hamid 1,2,7, Anand Sundaralingam ${ }^{3}$, Alice Evans ${ }^{4}$, Roshan Karthikappallil ${ }^{4}$, Tao Dong ${ }^{1,2}$, Najib M. Rahman ${ }^{3,4,5,6}$, Nikolaos I. Kanellakis ${ }^{3,4,5,6}$

${ }^{1}$ Chinese Academy of Medical Sciences Oxford Institute, Nuffield Dept of Medicine, University of Oxford, Oxford, UK. ${ }^{2}$ MRC Human Immunology Unit, MRC Weatherall Institute of Molecular Medicine, University of Oxford, Oxford, UK. ${ }^{3}$ Oxford Centre for Respiratory Medicine, Churchill Hospital, Oxford University Hospitals NHS Foundation Trust, Oxford, UK. ${ }^{4}$ Laboratory of Pleural and Lung Cancer Translational Research, Nuffield Dept of Medicine, University of Oxford, Oxford, UK. ${ }^{5}$ National Institute for Health Research Oxford Biomedical Research Centre, University of Oxford, Oxford, UK. ${ }^{6}$ Oxford Respiratory Trials Unit, Nuffield Dept of Medicine, University of Oxford, Oxford, UK.

${ }^{7}$ Both authors contributed equally.

\section{Author contributions}

All authors wrote sections and reviewed the manuscript.

\section{Support statement}

N.I. Kanellakis and N.M. Rahman are supported by a National Institute for Health Research Oxford Biomedical Research Centre grant. T. Dong is supported by the Medical Research Council, UK. 


\section{Conflict of interest}

None declared.

\section{References}

1. Spagnolo P, Cordier JF, Cottin V. Connective tissue diseases, multimorbidity and the ageing lung. Eur Respir J 2016; 47 1535-1558.

2. Light RW, Lee YCG. Textbook of Pleural Diseases. 3rd Edn. Boca Raton, CRC Press, Taylor \& Francis Group, 2016.

3. Smolen JS, Aletaha D, Mclnnes IB. Rheumatoid arthritis. Lancet 2016; 388: 2023-2038.

4. Scott DL, Wolfe F, Huizinga TW. Rheumatoid arthritis. Lancet 2010; 376: 1094-1108.

5. Silman AJ, Pearson JE. Epidemiology and genetics of rheumatoid arthritis. Arthritis Res 2002; 4: Suppl. 3, S265-S272.

6. Halverson PB. Extraarticular manifestations of rheumatoid arthritis. Orthop Nurs 1995; 14: 47-50.

7. Jurik AG, Graudal H. Pleurisy in rheumatoid arthritis. Scand J Rheumatol 1983; 12: 75-80.

8. Balbir-Gurman A, Yigla M, Nahir AM, et al. Rheumatoid pleural effusion. Semin Arthritis Rheum 2006; 35: 368-378.

9. Helmers R, Galvin J, Hunninghake GW. Pulmonary manifestations associated with rheumatoid arthritis. Chest 1991; 100: 235-238

10. Horler AR, Thompson M. The pleural and pulmonary complications of rheumatoid arthritis. Ann Intern Med 1959; 51: 1179-1203.

11. Reamy BV, Williams PM, Odom MR. Pleuritic chest pain sorting through the differential diagnosis. Am Fam Physician 2017; 96: 306-312

12. Karkhanis VS, Joshi JM. Pleural effusion: diagnosis, treatment and management. Open Access Emerg Med 2012; 4: 31-52.

13. Schneider F, Gruden J, Tazelaar HD, et al. Pleuropulmonary pathology in patients with rheumatic disease. Arch Pathol Lab Med 2012; 136: 1242-1252.

14. Halla JT, Schrohenloher RE, Volanakis JE. Immune complexes and other laboratory features of pleural effusions: a comparison of rheumatoid arthritis, systemic lupus erythematosus, and other diseases. Ann Intern Med 1980; 92: 748-752

15. Sahn SA, Kaplan RL, Maulitz RM, et al. Rheumatoid pleurisy. observations on the development of low pleural fluid $\mathrm{pH}$ and glucose level. Arch Intern Med 1980; 140: 1237-1238.

16. Rodriguez-Zarco E, Vallejo-Benitez A, Otal-Salaverri C. Pleura effusion associate with rheumatoid arthritis: diagnostic clues. J Cytol 2019; 36: 222-223.

17. Lisnevskaia L, Murphy G, Isenberg D. Systemic lupus erythematosus. Lancet 2014; 384: 1878-1888.

18. Tsokos GC. Systemic lupus erythematosus. N EnglJ Med 2011; 365: 2110-2121.

19. Boddaert J, Huong DL, Amoura Z, et al. Late-onset systemic lupus erythematosus: a personal series of 47 patients and pooled analysis of 714 cases in the literature. Medicine (Baltimore) 2004; 83: 348-359.

20. Aringer M, Costenbader K, Daikh D, et al. 2019 European League Against Rheumatism/American College of Rheumatology Classification Criteria for Systemic Lupus Erythematosus. Arthritis Rheumatol 2019; 71: 1400-1412.

21. Keane MP, Lynch JP 3rd, Pleuropulmonary manifestations of systemic lupus erythematosus. Thorax 2000; 55: 159-166.

22. Vitali C, Bencivelli W, Isenberg DA, et al. Disease activity in systemic lupus erythematosus: report of the Consensus Study Group of the European Workshop for Rheumatology Research. II. Identification of the variables indicative of disease activity and their use in the development of an activity score. The European Consensus Study Group for Disease Activity in SLE. Clin Exp Rheumatol 1992; 10: 541-547.

23. Cervera R, Khamashta MA, Font J, et al. Systemic lupus erythematosus: clinical and immunologic patterns of disease expression in a cohort of 1,000 patients. The European Working Party on Systemic Lupus Erythematosus. Medicine (Baltimore) 1993; 72: 113-124.

24. Man BL, Mok CC. Serositis related to systemic lupus erythematosus: prevalence and outcome. Lupus 2005; 14: 822-826.

25. Haupt HM, Moore GW, Hutchins GM. The lung in systemic lupus erythematosus. Analysis of the pathologic changes in 120 patients. Am J Med 1981; 71: 791-798.

26. Bouros D, Pneumatikos I, Tzouvelekis A. Pleural involvement in systemic autoimmune disorders. Respiration 2008; 75 : 361-371.

27. Smith PR, Nacht RI. Drug-induced lupus pleuritis mimicking pleural space infection. Chest 1992; 101: 268-269.

28. Starobin D, Guller V, Gurevich A, et al. Minocycline induced lupus with yellow colored chylous exudative pleural effusion. Respir Med Case Rep 2017; 22: 113-116.

29. Good JT, Jr., King TE, Antony VB, et al. Lupus pleuritis. Clinica features and pleural fluid characteristics with special reference to pleural fluid antinuclear antibodies. Chest 1983; 84 714-718

30. Porcel JM, Ordi-Ros J, Esquerda A, et al. Antinuclear antibody testing in pleural fluid for the diagnosis of lupus pleuritis. Lupus 2007; 16: 25-27.

31. Wang DY, Yang PC, Yu WL, et al. Comparison of different diagnostic methods for lupus pleuritis and pericarditis: a prospective three-year study. J Formos Med Assoc 2000; 99: 375-380.

32. Chandrasekhar AJ, Robinson J, Barr L. Antibody deposition in the pleura: a finding in drug-induced lupus. J Allergy Clin Immunol 1978; 61: 399-402.

33. Pertschuk LP, Moccia LF, Rosen Y, et al. Acute pulmonary complications in systemic lupus erythematosus. Immunofluorescence and light microscopic study. Am J Clin Pathol 1977; 68: 553-557.

34. Kaine JL. Refractory massive pleural effusion in systemic lupus erythematosus treated with talc poudrage. Ann Rheum Dis 1985; 44: 61-64.

35. Gilleece MH, Evans CC, Bucknall RC. Steroid resistant pleural effusion in systemic lupus erythematosus treated with tetracycline pleurodesis. Ann Rheum Dis 1988; 47 1031-1032.

36. Cervera R, Khamashta MA, Font J, et al. Morbidity and mortality in systemic lupus erythematosus during a 10-year period: a comparison of early and late manifestations in a cohort of 1,000 patients. Medicine (Baltimore) 2003; 82: 299-308.

37. Churg J, Strauss L. Allergic granulomatosis, allergic angiitis, and periarteritis nodosa. Am J Pathol 1951; 27: 277-301.

38. Lanham JG, Elkon KB, Pusey CD, et al. Systemic vasculitis with asthma and eosinophilia: a clinical approach to the ChurgStrauss syndrome. Medicine (Baltimore) 1984; 63: 65-81.

39. Cottin V, Bel E, Bottero P, et al. Respiratory manifestations of eosinophilic granulomatosis with polyangiitis (Churg-Strauss) Eur RespirJ 2016; 48: 1429-1441.

40. Szczeklik W, Sokolowska B, Mastalerz L, et al. Pulmonary findings in Churg-Strauss syndrome in chest $X$-rays and high resolution computed tomography at the time of initial diagnosis. Clin Rheumatol 2010; 29: 1127-1134

41. Erzurum SC, Underwood GA, Hamilos DL, et al. Pleural effusion in Churg-Strauss syndrome. Chest 1989; 95: 1357-1359.

42. Buschman DL, Waldron JA, Jr., King TE, Jr. Churg-Strauss pulmonary vasculitis. High-resolution computed tomography scanning and pathologic findings. Am Rev Respir Dis 1990; 142: 458-461.

43. Sinico RA, Di Toma L, Maggiore U, et al. Prevalence and clinical significance of antineutrophil cytoplasmic antibodies 
in Churg-Strauss syndrome. Arthritis Rheum 2005; 52: 2926-2935.

44. Frankel SK, Jayne D. The pulmonary vasculitides. Clin Chest Med 2010; 31: 519-536.

45. Frankel SK, Schwarz MI. The pulmonary vasculitides. Am J Respir Crit Care Med 2012; 186: 216-224.

46. Pinching AJ, Lockwood CM, Pussell BA, et al. Wegener's granulomatosis: observations on 18 patients with severe renal disease. Q J Med 1983; 52: 435-460.

47. Krupsky M, Landau Z, Lifschitz-Mercer B, et al. Wegener's granulomatosis with peripheral eosinophilia. Atypical variant of a classic disease. Chest 1993; 104: 1290-1292.

48. Fauci AS, Haynes BF, Katz P, et al. Wegener's granulomatosis: prospective clinical and therapeutic experience with 85 patients for 21 years. Ann Intern Med 1983; 98: 76-85.

49. Cordier JF, Valeyre D, Guillevin L, et al. Pulmonary Wegener's granulomatosis. A clinical and imaging study of 77 cases. Chest 1990; 97: 906-912.

50. Weir IH, Muller NL, Chiles C, et al. Wegener's granulomatosis: findings from computed tomography of the chest in 10 patients. Can Assoc Radiol J 1992; 43: 31-34.

51. Bambery P, Katariya S, Sakhuja V, et al. Wegener's granulomatosis in north India. Radiologic manifestations in eleven patients. Acta Radiol 1988; 29: 11-13.

52. Joseph J, Sahn SA. Connective tissue diseases and the pleura. Chest 1993; 104: 262-270.

53. Wolffenbuttel BH, Weber RF, Kho GS. Pyopneumothorax: a rare complication of Wegener's granulomatosis. EurJ Respir Dis 1985; 67: 223-227.

54. Joseph CG, Darrah E, Shah AA, et al. Association of the autoimmune disease scleroderma with an immunologic response to cancer. Science 2014; 343: 152-157.

55. Denton CP, Khanna D. Systemic sclerosis. Lancet 2017; 390 : 1685-1699.

56. Thompson AE, Pope JE. A study of the frequency of pericardial and pleural effusions in scleroderma. Br J Rheumatol 1998; 37: 1320-1323.

57. Kimura K, Ezoe K, Yokozeki $\mathrm{H}$, et al. Elevated serum CA125 in progressive systemic sclerosis with pleural effusion. J Dermatol 1995; 22: 28-31.

58. Reveille JD. Major histocompatibility genes and ankylosing spondylitis. Best Pract Res Clin Rheumatol 2006; 20: 601-609.

59. Maxwell LJ, Zochling J, Boonen A, et al. TNF-alpha inhibitors for ankylosing spondylitis. Cochrane Database Syst Rev 2015; 4: CD005468.

60. Rosenow E, Strimlan CV, Muhm JR, et al. Pleuropulmonary manifestations of ankylosing spondylitis. Mayo Clin Proc 1977; 52: 641-649.

61. Kelly D, O'Connell O, Henry M. Adalimumab-induced lupus serositis. BMJ Case Rep 2015; 2015: bcr2014207323.

62. Bottai M, Tjarnlund A, Santoni G, et al. EULAR/ACR classification criteria for adult and juvenile idiopathic inflammatory myopathies and their major subgroups: a methodology report. RMD Open 2017; 3: e000507.

63. Schiopu E, Phillips K, MacDonald PM, et al. Predictors of survival in a cohort of patients with polymyositis and dermatomyositis: effect of corticosteroids, methotrexate and azathioprine. Arthritis Res Ther 2012; 14: R22.

64. Miyata M, Fukaya E, Takagi T, et al. Two patients with polymyositis or dermatomyositis complicated with massive pleural effusion. Intern Med 1998; 37: 1058-1063.

65. Fox RI. Sjogren's syndrome. Lancet 2005; 366: 321-331.

66. Mariette X, Criswell LA. Primary Sjogren's Syndrome. N Engl J Med 2018; 378: 931-939.
67. Alamanos $\mathrm{Y}$, Tsifetaki N, Voulgari PV, et al. Epidemiology of primary Sjogren's syndrome in north-west Greece, 19822003. Rheumatology (Oxford) 2006; 45: 187-191.

68. Qin B, Wang J, Yang Z, et al. Epidemiology of primary Sjogren's syndrome: a systematic review and meta-analysis. Ann Rheum Dis 2015; 74: 1983-1989.

69. Romao VC, Talarico R, Scire CA, et al. Sjogren's syndrome: state of the art on clinical practice guidelines. RMD Open 2018; 4: Suppl. 1, e000789.

70. Stefanski AL, Tomiak C, Pleyer U, et al. The diagnosis and treatment of Sjogren's syndrome. Dtsch Arztebl Int 2017; 114: 354-361.

71. Teshigawara K, Kakizaki S, Horiya M, et al. Primary Sjogren's syndrome complicated by bilateral pleural effusion. Respirology 2008; 13: 155-158.

72. Kawamata $\mathrm{K}$, Haraoka $\mathrm{H}$, Hirohata $\mathrm{S}$, et al. Pleurisy in primary Sjogren's syndrome: T cell receptor beta-chain variable region gene bias and local autoantibody production in the pleural effusion. Clin Exp Rheumatol 1997; 15: 193-196.

73. Bloch KJ, Buchanan WW, Wohl MJ, et al. Sjogren's syndrome. A clinical, pathological, and serological study of sixty-two cases. 1965. Medicine (Baltimore) 1992; 71: 386-401.

74. Constantopoulos SH, Papadimitriou CS, Moutsopoulos HM. Respiratory manifestations in primary Sjogren's syndrome. A clinical, functional, and histologic study. Chest 1985; 88: 226-229.

75. Papathanasiou MP, Constantopoulos SH, Tsampoulas C, et al. Reappraisal of respiratory abnormalities in primary and secondary Sjogren's syndrome. A controlled study. Chest 1986; 90: 370-374.

76. Tanaka A, Tohda Y, Fukuoka M, et al. [A case of Sjogren's syndrome with pleural effusion]. Nihon Kokyuki Gakkai Zasshi 2000; 38: 628-631.

77. Ogihara T, Nakatani A, Ito $\mathrm{H}$, et al. Sjogren's syndrome with pleural effusion. Intern Med 1995; 34: 811-814.

78. Kashiwabara K, Kishi K, Narushima K, et al. [Primary Sjogren's syndrome accompanied by pleural effusion]. Nihon Kyobu Shikkan Gakkai Zasshi 1995; 33: 1325-1329.

79. Sharp GC, Irvin WS, Tan EM, et al. Mixed connective tissue disease--an apparently distinct rheumatic disease syndrome associated with a specific antibody to an extractable nuclear antigen (ENA). Am J Med 1972; 52: 148-159.

80. Chaigne B, Scire CA, Talarico R, et al. Mixed connective tissue disease: state of the art on clinical practice guidelines. $R M D$ Open 2018; 4: Suppl. 1, e000783.

81. Prakash UB. Respiratory complications in mixed connective tissue disease. Clin Chest Med 1998; 19: 733-746.

82. Battista G, Zompatori M, Poletti V, et al. Thoracic manifestations of the less common collagen diseases. A pictorial essay. Radiol Med 2003; 106: 445-451.

83. Bull TM, Fagan KA, Badesch DB. Pulmonary vascular manifestations of mixed connective tissue disease. Rheum Dis Clin North Am 2005; 31: 451-464.

84. Prakash UB, Luthra HS, Divertie MB. Intrathoracic manifestations in mixed connective tissue disease. Mayo Clin Proc 1985; 60: 813-821.

85. Ilan Y, Ben-Yehuda A, Okon E, et al. Mixed connective tissue disease presenting as a left sided pleural effusion. Ann Rheum Dis 1992; 51: 1157-1158.

86. Hoogsteden HC, van Dongen JJ, van der Kwast TH, et al. Bilateral exudative pleuritis, an unusual pulmonary onset of mixed connective tissue disease. Respiration 1985; 48: 164-167. 